Article

\title{
A guiding framework for needs assessment evaluations to em- bed digital tools with Indigenous communities
}

\author{
Jasmin Bhawra ${ }^{1}$, Marisa Claire Buchan ${ }^{2}$, Kelly Skinner ${ }^{2}$, Duane Favel ${ }^{3}$, and Tarun Reddy Katapally 4,* \\ 1 Johnson Shoyama Graduate School of Public Policy, University of Saskatchewan; jasmin.bhawra@usask.ca \\ 2 School of Public Health Sciences, Faculty of Health, University of Waterloo; mcbuchan@uwaterloo.ca; kskin- \\ ner@uwaterloo.ca \\ 3 Northern Village of Île-à-la-Crosse, Île-à-la-Crosse, SK, Canada; duane.favel.ile@gmail.com \\ 4 School of Health Studies, Faculty of Health Sciences, Western University; tkatapa@uwo.ca \\ * Correspondence: tkatapa@uwo.ca
}

\begin{abstract}
In community-based participatory projects, needs assessments are one of the first steps to identify priority areas. Access-related issues often pose significant barriers to participation for rural and remote communities, particularly Indigenous communities which have a complicated relationship with academia due to a history of exploitation and trauma. In order to bridge this gap, work with Indigenous communities requires consistent and meaningful engagement. The prominence of digital devices (i.e., smartphones) offers an unparalleled opportunity to ethically and equitably engage citizens across jurisdictions, particularly in remote communities. We propose a framework to guide needs assessments which embed digital tools in partnership with Indigenous communities. Guided by this framework, a needs assessment was conducted with a subarctic Métis community in Saskatchewan, Canada. This project is governed by a Citizen Scientist Advisory Council which includes Traditional Knowledge Keepers, Elders, and youth. An environmental scan of relevant programs, key informant interviews, and focus groups were conducted to systematically identify community priority areas. Given the timing of the needs assessment, the community identified the Coronavirus pandemic as a key priority area requiring digital initiatives. Recommendations for community-based needs assessments to conceptualize and implement digital infrastructure are put forward, with an emphasis on self-governance and data sovereignty.
\end{abstract}

Keywords: Community Engagement; Needs Assessment; Digital Tools; Indigenous Health; Data Sovereignty; Evaluation Framework.

\section{Introduction}

Community engagement has been the cornerstone of participatory action research in a range of disciplines. Community involvement in research can range from leadership to collective decision-making in order to guide the development of community-driven initiatives (Jull, Giles, and Graham 2017; Wallerstein et al. 2017). Every community has a unique culture and identity, hence community members are the experts regarding their diverse histories, priority areas, and successes (Smith 2021; Datta 2018; Wallerstein et al. 2017). As a result, the sustainability of community-based research initiatives largely depends on meaningful community engagement (Carr-Hill and Street 2008; Mason et al. 2008; Popay et al. 2007; Narayan 2002; Cairncross et al. 2002; Pratchett et al. 2009). There is a considerable body of research which has established the need for authentic community-research partnerships which empower citizens and ensure relevant and sustainable solutions (Smith 2021; Rights 2011; Datta 2018; Wallerstein et al. 2017).

For groups that have been marginalized or disadvantaged, community-engaged research that prioritizes citizens' control is critical for successful uptake, implementation, and longevity of community initiatives (Cyril et al. 2015). Collaboration in research and 
evaluation projects can provide a platform to amplify citizens' voices and ensure necessary representation in decision-making. Such initiatives must be developed in alignment with a community's cultural framework, expectations, and vision (Wehipeihana, Davidson, and Mckegg 2010) in order to support continuous and meaningful engagement throughout the project.

Many communities have a complicated relationship with research as a result of colonialism, and the trauma of exploitation and discrimination has continued to limit participation of some communities in academic partnerships (Sylvestre et al. 2018). Indigenous Peoples in Canada experience a disproportionate number of health, economic, and social inequalities compared to non-Indigenous Canadians (Frohlich, Ross, and Richmond 2006). Many of these health (e.g., elevated risk of chronic and communicable diseases) (Public Health Agency of Canada 2018; Statistics Canada 2017; Waldram, Herring, and Young, n.d.; Marrone 2007)), socioeconomic (e.g., elevated levels of unemployment and poverty) (Central Urban Métis Federation Inc., Kinistin Saulteaux Nation, and Saskatoon Health Region 2010; Statistics Canada 2017; King, Smith, and Gracey 2009; Gracey and King 2009), and social (e.g., racism and discrimination) (Central Urban Métis Federation Inc., Kinistin Saulteaux Nation, and Saskatoon Health Region 2010; Statistics Canada 2017; Gracey and King 2009; King, Smith, and Gracey 2009)) inequities can be traced back to the long term impacts of assimilation, colonization, residential schools, and a lack of access to healthcare (Central Urban Métis Federation Inc., Kinistin Saulteaux Nation, and Saskatoon Health Region 2010; Statistics Canada 2017; Waldram, Herring, and Young, n.d.; Gracey and King 2009; King, Smith, and Gracey 2009). In order to bridge this gap, and more importantly, to work towards Truth and Reconciliation (Marsh et al. 2015), work with Indigenous Peoples must be community-driven, and community-academia relationship building is essential before exploring initiative co-conceptualization.

One of the first steps in building a relationship to learn more about community priorities is to conduct a needs assessment. A needs assessment is a research and evaluation method for identifying areas for improvement or gaps in current policies, programs, and services (Watkins, Meiers, and Visser 2012). When conducted in partnership with the community of focus, needs assessments can identify priority areas and be used to develop innovative solutions, while leveraging the existing knowledge and systems that communities have in place (Skinner et al. 2021). Needs assessment paves the path for understanding the value and applicability of research for community members, incorporating key perspectives, and building authentic partnerships with communities to support effective translation of research into practice.

For rural, remote, and northern communities within Canada, issues related to access (e.g., geographic location, transportation, methods of communication, etc.) pose significant barriers (Pelletier et al. 2020). Digital devices, and in particular, the extensive usage of smartphones (O'Dea 2021) offers a new opportunity to ethically and equitably engage citizens (Katapally 2020a). The role of digital technology in providing healthcare access increased significantly since the onset of the Coronavirus (COVID-19) pandemic (Katapally 2020b). The COVID-19 pandemic has catalyzed the use of digital devices in delivering essential services and programs to communities (Whitelaw et al. 2020).

Given the increasing prominence of digital devices for addressing accessibility of services in partnership with Indigenous communities (Katapally, Kannan, and Kwabia 2021; O'Donnell et al. 2016), it is critical to evaluate the conceptualization, implementation, and knowledge dissemination of digital tools. However, there is little guidance to date on how to ethically evaluate digital tools, particularly in partnership with rural and remote communities. This paper proposes a framework for conducting community-based needs assessments in the digital age, which is the first step in developing an evaluation framework for digital tools. To co-develop this framework with community partners, a needs assessment was conducted with a subarctic Indigenous community in Canada, demonstrating an applied example to identify key priority areas for community health, barriers and supports, 
and existing digital infrastructure to successfully implement digital health tools and platforms.

\section{Materials and Methods}

\subsection{Design}

A mixed methods needs assessment utilizing focus groups, interviews, and document review, was conducted between February and May 2020 in Île-à-la-Crosse, Saskatchewan, Canada. The needs assessment is Phase 1 of a larger evaluation strategy to develop and implement culturally-appropriate digital tools for community health. Phase 1 involved identifying core health issues and desired support in the community of Ile-à-la-Crosse. Based on the needs assessment findings, Phase 2 involves the development of tailored digital health tools and programming to support digital literacy.

Digital tools and platforms refer collectively to all programs, applications (apps), and software that are accessible through digital devices (i.e., smartphones, computers, smartwatches). Digital tools can be used for a variety of purposes, ranging from project management, healthcare delivery, to mass communication. Digital infrastructure, however, refers to the larger systems which support access and use of these digital tools, platforms, and devices; they include but are not limited to internet, satellites, cellular networks, and data storage centres.

As part of Phase 2, digital literacy programs and tailored digital health tools will be pilot tested and adapted prior to their implementation. In Phase 3, a process evaluation will be conducted to assess the reach, uptake, and use of digital health tools and digital literacy programming. Integrated knowledge translation will be conducted during all phases to ensure continuous feedback, communication, and knowledge sharing with all relevant stakeholder groups.

This project is governed by a Citizen Scientist Advisory Council which includes Traditional Knowledge Keepers, Elders, youth, and researchers. The Council represents the needs and interests of the community, and guides the project development, implementation, and evaluation. Council members are provided with Can \$150 (US \$119.30) as honoraria for each meeting to respect their time, knowledge, and guidance contributions.

For the needs assessment (Phase 1), unstructured online focus groups were conducted with the Council, and key informant interviews were conducted with decision makers in the community. The Council also identified appropriate data sources for the document review. A novel framework for conducting community-based needs assessments for digital tool development was conceptualized. Figure 1 describes the overarching framework that guided the needs assessment.

This framework is driven by core questions necessary to identify community priority areas that can be addressed by developing and implementing digital tools. These questions can be used to aid needs assessments in a range of areas, including but not limited to community health and wellness projects.

Following identification of community priority areas, five themes aid in the assessment of community needs to develop and implement digital tools: i) current supports; ii) desired supports; iii) barriers; iv) community engagement; and v) digital access and connectivity. Thereafter, a set of sub-questions are embedded in each needs assessment theme. The questions assigned to each theme can be used to guide needs assessments of any priority area identified by community stakeholders as suitable for addressing with digital tools.

\subsection{Setting}

Established in 1776, Île-à-la-Crosse is a northern subarctic community with road access in northwest Saskatchewan. Sakitawak, the Cree name for Île-à-la-Crosse, means "where the rivers meet," hence the community was an historically important meeting point for the fur trade in the 1800s (Cameco Corp 2020; McLennan, n.d.). The community lies on a peninsula on the Churchill River, near the intersections with the Beaver River and 
Canoe River systems. Île-à-la-Crosse has a rich history dating back to the fur trade. Due to its strategic location, Montreal-based fur traders established the first trading point in Île-àla-Crosse in 1776, making the community Saskatchewan's oldest continually inhabited community next to Cumberland House ("The Encyclopedia of Saskatchewan: Île-à-LaCrosse," n.d.). In 1821, Île-à-la-Crosse became the headquarters for the Hudson's Bay Company's operations in the territory. In 1860, the first convent was established bringing Western culture, medical services, and education to the community.

Île-à-la-Crosse has a population of roughly 1,300 people (Statistics Canada 2017). Consistent with Indigenous populations across Canada, the average age of the community is 32.7 years, roughly 10 years younger than the Canadian non-Indigenous average (Statistics Canada 2017). Census data report that just under half $(44 \%)$ of the community's population is under the age of $25,46.3 \%$ are aged $25-64$, and $9.3 \%$ aged 65 and over (Statistics Canada 2017). Members of the community predominantly identify as Métis (77\%), with some identifying as First Nations (18\%), multiple Indigenous responses (1.2\%), and non-Indigenous (2.7\%) (Statistics Canada 2017). Many community members are employed in a traditional manner utilizing resources of the land (e.g., hunting, fishing, trapping), others in a less traditional manner (e.g., lumbering, tourism, wild rice harvesting), and some are employed through the hospital and schools. The community currently has one elementary school with approximately 200 students from preschool to Grade 6, and one high school serving Grades 7-12 with adult educational programming. Île-à-la-Crosse has a regional hospital with Emergency Services, which includes a health services centre with a total of 29 beds. Other infrastructure of the community includes a Royal Canadian Mounted Police (RCMP) station, a village office, volunteer fire brigade, and a catholic church (Favel and Roy 2013).

\subsection{Needs Assessment Evaluation}

Needs assessments are a common type of formative evaluation and are often considered a form of strategic or program planning, even more than they are considered a type of evaluation. Needs assessments can occur at different points, both before and during an evaluation or program implementation; however, they are most effective when they are conducted before a new initiative starts or before a decision is made about what to do (e.g., how to make program changes) (Watkins, Meiers, and Visser 2012). Typically a needs assessment includes: 1) collecting information about the community; 2) determining what needs are already being met; and, 3) determining what needs are not being met and what resources are available to meet those needs (Stufflebeam and Shinkfield 2007). Since the community is building a vision to integrate digital technology and infrastructure as part of its growth, a needs assessment can provide the formative information necessary to understand what the needs are, including who (i.e., players, partners), and what (i.e., information sources) would need to be involved, what opportunities exist to address the needs, and setting priorities for action with key community stakeholders (Health Quality Ontario 2009). As a starting point and rationale for this needs assessment, the community of Île-à-la-Crosse values the potential that technology has to improve health communication, information reach, access to resources, and care, and was interested in identifying priority areas to begin to build this digital infrastructure. Given the timing of the COVID-19 pandemic, being responsive to community health needs were key priorities that they wanted to start addressing using a digital platform. This needs assessment facilitated and enabled new conversations around key focus areas and next steps.

The approach to evaluation was culturally-responsive and included empowerment principles (Askew, Beverly, and Jay 2012; Chouinard and Cram 2020; Fetterman 1994). Empowerment evaluation intends to foster self-determination. The empowerment approach (Fetterman 1994) involved community members - represented through the Citizen Scientist Advisory Council - engaging in co-production of evaluation design and implementation by establishing key objectives for the evaluation, informing the 
evaluation questions, building relevant and culturally responsive indicators, developing focus group guides, leading recruitment and data collection, and interpreting results (Voegeli 2021). In this way, the approach incorporated community and Indigenous knowledges as well as Western knowledge, in a similar approach to Two-Eyed Seeing (Bartlett, Marshall, and Marshall 2012; Iwama et al. 2009; Martin 2012). Using these needs assessment evaluation results, the community will identify emerging needs, potential application issues, and will work with the researchers to continue shaping project development and implementation.

\subsection{Data Collection}

In order to obtain an in-depth understanding of the key priority areas and supports within the community of Île-à-la-Crosse, this needs assessment used a mixed methods approach. A total of two focus groups were conducted by members of the research team in Île-à-la-Crosse with the Citizen Scientist Advisory Council in May 2020. Focus group participants were asked to describe community priority areas, supports, and barriers, as well as experience and comfort with digital tools.

Qualitative data were collected from key decision makers within the community. A purposeful sampling approach was employed in order to identify members of the community who could provide detailed and relevant information on community priorities, digital infrastructure, supports, and challenges. Three key Informant interviews were conducted by members of the research team in Île-à-la-Crosse between February and April 2020. Interviews were conducted one-on-one and followed a semi-structured interview format.

An environmental scan was conducted in February 2020 of current school and community policies and programs. Published reports, meeting memos, community social media accounts, and the Île-à-la-Crosse website were reviewed for existing policies and programs.

\subsection{Data Analysis}

The key informant interviews and focus groups were audio-recorded and transcribed. A thematic analysis was conducted in order to systematically identify key topic areas and patterns across discussions. A list was created for the key informant interviews and focus groups, respectively, organizing the discussion topics by theme.

Separate analyses were conducted for key informant interviews and focus group discussions, however evidence was combined afterward to develop key themes and subthemes in key priority areas for the community, community supports and barriers, as well as digital connectivity and infrastructure needs. Quotations have not been provided to protect the privacy of key informants and community members.

All documents identified through the environmental scan were reviewed for key themes. A list of existing school and community programs was compiled and organized by theme (i.e., education-focused, nutrition-focused, health-focused, etc.). Follow-up conversations with key informants verified the continued planning and provision of these programs.

\section{Results}

\subsection{Needs assessment overview}

A framework was developed to guide community needs assessments focused on the application of digital tools. The framework provides a series of general questions in five key topic areas (Figure 1) to aid other projects in conducting community needs assessments, and can be adapted across communities and jurisdictions. 


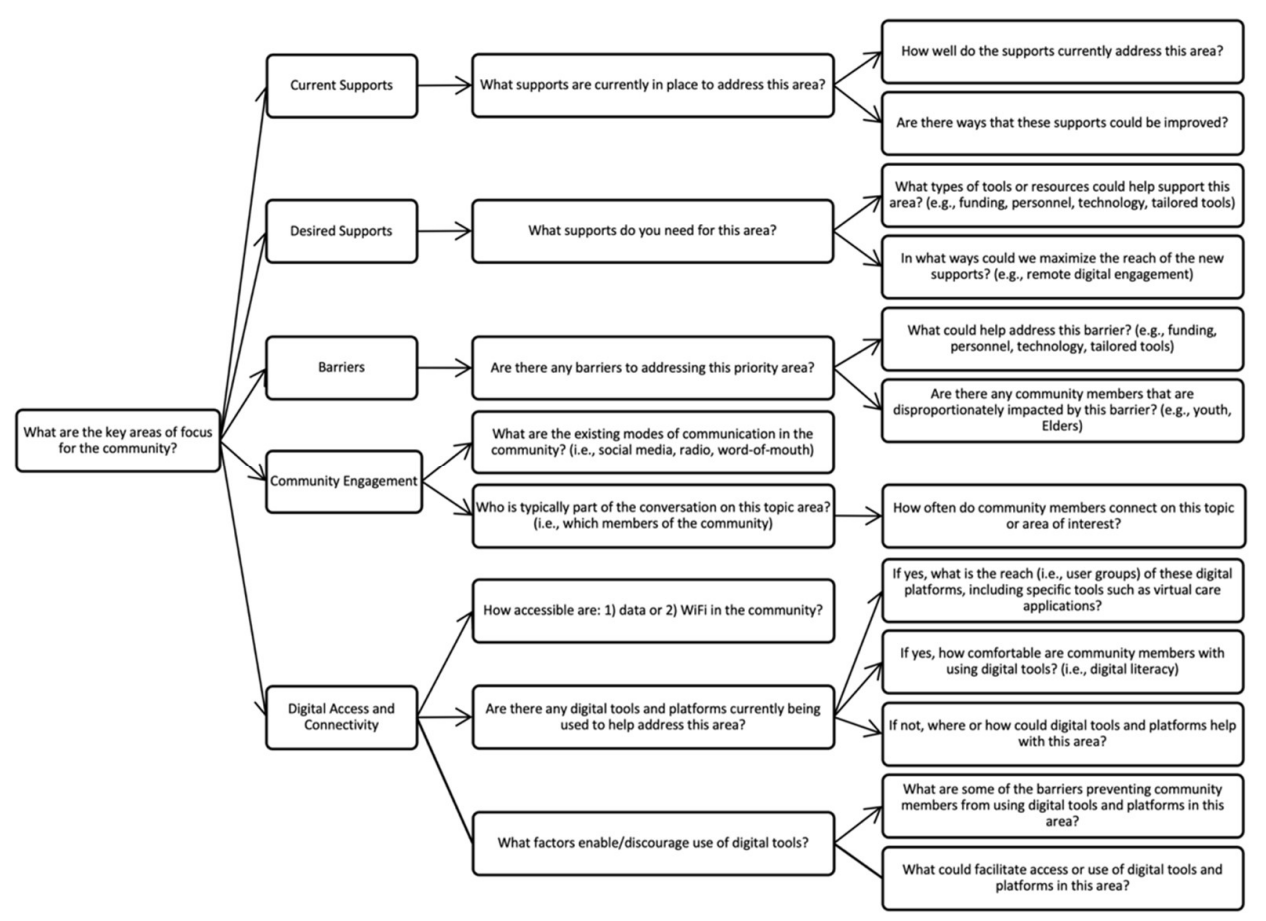

Figure 1. A Guiding Framework for Community-Based Needs Assessments Embedding Digital Tools.

The needs assessment guiding framework informed specific discussions of key issues in the community of Île-à-la-Crosse. Key informant interviews and focus group discussions commenced by asking about priority areas - "what are the key areas of focus for the community?" In all conversations - including a document review of initiatives in Île-à-la-Crosse - health was highlighted as a current priority area; hence, questions in the guiding framework were tailored to fit a needs assessment focused on community health. The following five overarching evaluation questions were used to guide the evaluation: i) What are the prominent health issues facing residents of Ille-à-la-Crosse?; ii) What supports are currently available to help residents address prominent health issues in the community?; iii) What types of barriers do community members face to accessing services to manage their health?; iv) How is health-related information currently shared in the community?; and v) To what extent are health services and information currently managed digitally/electronically? The evaluation questions were kept broad to capture a range of perspectives. An evaluation matrix linking the proposed evaluation questions to their respective sub-questions, indicators, and data collection tools is outlined in Table 1.

Table 1. Evaluation Matrix of a Needs Assessment focused on Community and Digital Health

\begin{tabular}{|c|c|c|c|}
\hline Original framework question & Questions \& Sub-questions & Indicators & Data Sources \\
\hline \multicolumn{4}{|l|}{ Priority areas } \\
\hline $\begin{array}{l}\text { 1. What are the key areas of fo- } \\
\text { cus for the community? }\end{array}$ & $\begin{array}{l}\text { What are the prominent } \\
\text { health issues facing residents } \\
\text { of Île-à-la-Crosse? } \\
\text { What are the key health } \\
\text { issues among children } \\
\text { and youth in the commu- } \\
\text { nity? }\end{array}$ & $\begin{array}{l}\text { Qualitative feedback } \\
\text { from key informant } \\
\text { interviews and focus } \\
\text { groups }\end{array}$ & $\begin{array}{l}\text { Key informant inter- } \\
\text { views with the deci- } \\
\text { sion makers of the } \\
\text { school division and } \\
\text { community }\end{array}$ \\
\hline
\end{tabular}


1. What supports are currently in place to address this area?

2. How well do the supports currently address this area?

2.1. Are there ways that these supports could be improved?
- What supports are currently available to help residents address prominent health issues in the community?

- What types of supports are available at the i) school, and ii) community level?

- What factors influence the use of these supports?

- What are ways these supports could be adapted to better suit your community's needs?

\section{Desired supports}

3. What supports do you need for this area?

3.1. What types of tools or resources could help support this area (e.g., funding, personnel, technology, tailored tools)?

3.2. In what ways could we maximize the reach of new supports (e.g., remote digital engagement)?

- What supports do you wish were available to help residents address prominent health issues in the community?

- What type of supports would they be? (e.g., resources, infrastructure, programming, policies)

- In what ways could we enable more people to access the new supports (e.g., remote digital engagement)?

\section{Barriers}

4. Are there any barriers to addressing this priority area?

5. What could help overcome this barrier (e.g., funding, personnel, technology, tailored tools)?

5.1. Are there any community members that are disproportionately impacted by this barrier (e.g., youth, Elders)?
- What types of barriers do community members face to accessing services to manage their health?

- Are there ways to support the community to help them overcome these barriers?

- Are there specific barriers for children and youth in particular?
Qualitative feedback from key informant interviews and focus groups

School programs,

school policies, school Document review budget

Community programming

Community health infrastructure

Qualitative feedback from key informant interviews and focus groups

Key informant interviews with the decision makers of the school division and community

School programs, school policies, school Document review budget

Community programming

Community health infrastructure

\section{Qualitative feedback Key informant in-} from key informant interviews and focus groups terviews with the decision makers of the school division and community

Unstructured focus groups with the Citizen Scientist Advisory Council

\section{Community engagement}

6. What are the existing modes of communication in the community (i.e., social media, radio, word-of-mouth)?

6.1. Who is typically part of the conversation on this topic area (i.e., which members of the community)?

6.2. How often do community members connect on this topic or area of interest?
- How is health-related information currently shared in the community?

○ How did you find out (for community members) /communicate (for decision-makers) health information during the COVID-19 pandemic?
Qualitative feedback Key informant infrom key informant terviews with the interviews and focus decision makers of groups the school division and community

Unstructured focus groups with the Citizen Scientist Advisory Council 


\section{connectivity}

\section{How accessible is i) data, or} ii) WiFi in the community?

8. Are there any digital tools currently being used to help address this area?

8.1. If yes, what is the reach of these digital tools (e.g., user groups)?

8.2. If yes, how comfortable are community members with these digital tools (i.e., digital literacy)?

8.3. If not, where or how could a digital platform/tool help with this area?

9. What factors enable/discourage use of digital tools?

10. What are some barriers preventing community members from using digital tools in this area?

10.1. What could facilitate access or use of digital tools in this area?
- $\quad$ All questions from column 1.

- To what extent are health services and information currently managed digitally/ electronically?

- Do you see any benefit of increasing the digital infrastructure for health services in the community?

- What are some challenges applying digital tools to healthcare in the community?

\section{Qualitative feedback Key informant in- from key informant terviews with the interviews. decision makers of the school division Smartphone use and and community. access in the com- munity}

WiFi/data connectivity and access

\subsection{Key priority areas}

Four priority areas were identified through focus groups, key informant interviews, and document review (Figure 2). Given the timing of the discussion, the primary issue of concern was the COVID-19 pandemic. Many community members were worried about contracting the virus, and the risk it posed to Elders in the community. Of greater concern, however, was how COVID-19 exacerbated many existing health concerns including diabetes and hypertension in the community. For example, routine procedures were postponed and community members with other health conditions were not receiving routine healthcare during the height of the pandemic. The St. Joseph's Hospital and Health Centre services Île-à-la-Crosse and bordering communities, hence maintaining capacity for COVID-19 patients was a priority. COVID-19 exposed existing barriers in the healthcare system which are described in greater detail in the barriers to community health section. 


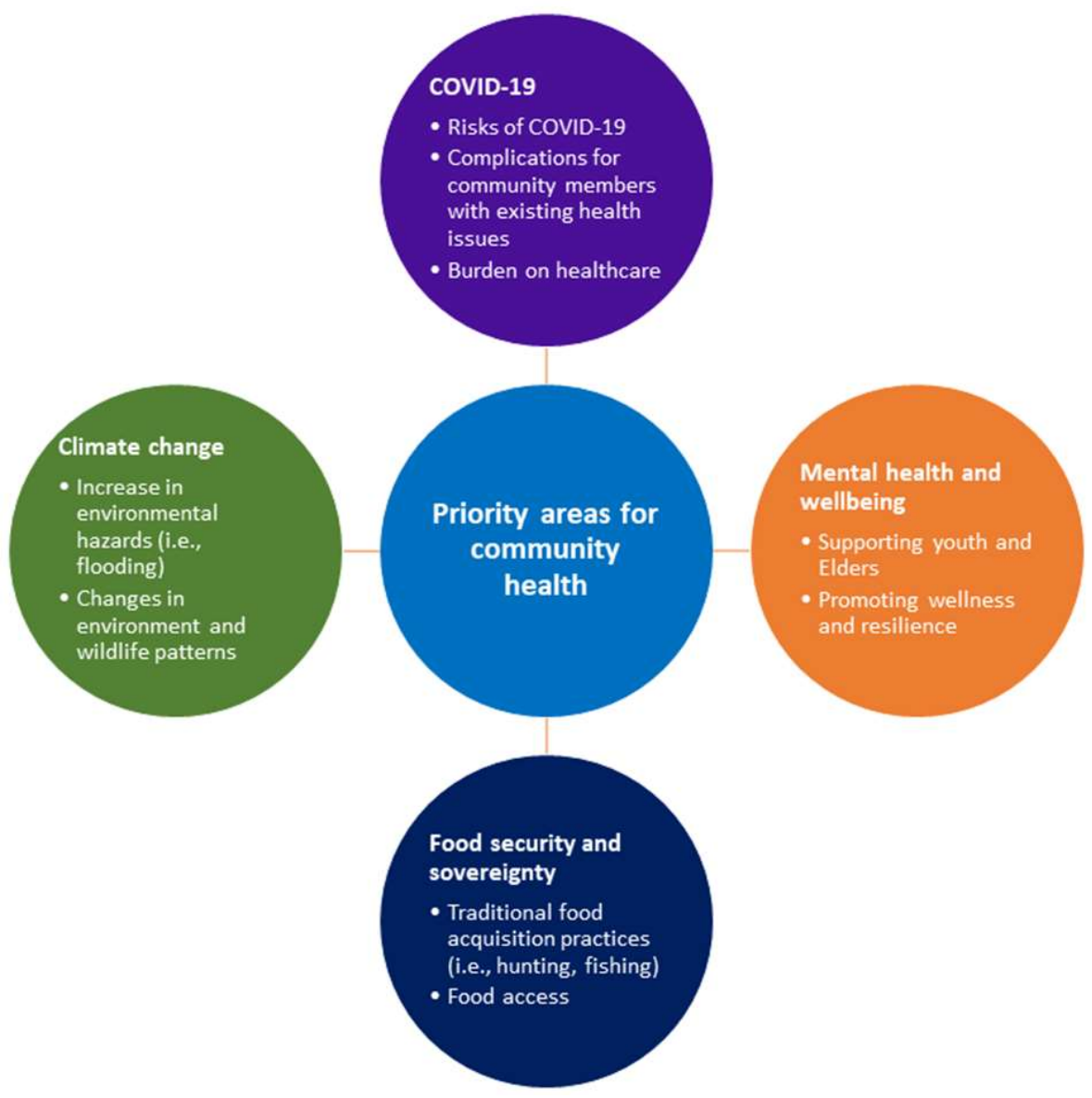

Figure 2. Summary of key priority health areas.

Another priority area discussed by many community members was climate change and the environment. Community members noted that changes in wildlife patterns, land use, and early winter ice road thaw were areas of concern, particularly due to the impact these factors have on traditional food acquisition practices (i.e., hunting) and food access. For instance, the geographic location of Île-à-la-Crosse is surrounded by a lake, and the main highway which connects the community to the land has experienced increased flooding in the past few years.

In addition to posing immediate danger to community members, food security and sovereignty are also closely linked to road access. While the community produces some of its own food through the local fishery and greenhouses, Ille-à-la-Crosse is still dependent on a food supply from the south (i.e., Saskatoon). During COVID-19, food access was further restricted due to limited transport and delivery of food products, which increased the risk of food insecurity for community members. Food insecurity was believed to be of bigger concern for Elders in the community compared to younger members. Younger community members expressed having the ability to source their own food in a variety of capacities (e.g., fishing in the lake), whereas Elders rely more heavily on community resources and support (e.g., grocery stores, friends and family).

Community members also discussed issues surrounding mental health and wellbeing. This topic was of particular concern for youth and Elders in the community. Community members discussed the importance of developing coping strategies, 
resilience, and supports to prevent mental health issues such as addictions from being exacerbated. Key informants emphasized the need to minimize the stigma around mental health and focus on holistic wellbeing as they work to develop strategies to improve community wellness.

\subsection{Community health supports}

Île-à-la-Crosse has been working on developing supports to improve community health through various initiatives. A document review identified a community-specific wellness model which has informed program development and planning over the past few years. The key components of the Île-à-la-Crosse wellness model are: i) healthy parenting; ii) healthy youth; iii) healthy communities; iv) Elders; v) healing towards wellness; and vi) food sovereignty. The Elders Lodge in the community provides support for holistic wellbeing by promoting intergenerational knowledge transmission, guidance to youth and community members, as well as land-based activities which improve bonding, cultural awareness, and mental and spiritual well-being among community members. The Elders Lodge hosts both drop-in and organized events.

Several initiatives have been developed to support food sovereignty in the community, including a greenhouse program where fruits and vegetables are grown and shared locally. This program is run in partnership with the school to increase food knowledge and skills among youth. In addition, after-school programs including traditional food education (i.e., cooking classes) and land-based activities (i.e., berry picking) led by Elders support the goals of the wellness model. The community is currently working on developing additional programs dedicated to improving mental wellness among adults, youth, and Elders.

\subsection{Barriers to community health}

When key informants were asked to identify barriers to community health, they described delays in access to timely health information. For example, daily COVID-19 tests conducted at the regional health centre in Île-à-la-Crosse were relayed to the provincial health authority; however, information about the total number of COVID-19 cases could take up to one week to be sent back to the community. This time lag restricted community decision-makers' ability to enact timely policy (i.e., contact tracing) and rapidly respond to managing cases.

A second barrier that was raised by community members was a delay in access to timely healthcare. The Île-à-la-Crosse hospital is a regional health service centre serving the community as well as surrounding areas. Community members noted that the load often exceeded the capacity of the single hospital, and some patients and procedures were relocated to hospitals and clinics in the larger city of Saskatoon, Saskatchewan. This was reported to be challenging for many community members as it was associated with longer wait times, long commutes, and sometimes required time off work. Many of these challenges were exacerbated during the COVID-19 pandemic. As a result of the pandemic, many medical centres and hospitals postponed routine and elective medical procedures in an attempt to accommodate the overwhelming influx of patients who contracted COVID-19. In addition, community members were advised to avoid spending time in health centres to limit risk of exposure to the virus. These COVIDrelated changes further delayed access to timely healthcare for many community members of Île-à-la-Crosse.

Several community members reported experiencing systemic discrimination in healthcare and social service settings outside of Île-à-la-Crosse. This was particularly exacerbated during the COVID-19 movement restrictions, where community members faced significant difficulties in accessing services and care in larger urban centres. Lastly, community members discussed a lack of awareness about some health topics, including where and how to access reliable health information. Some community members attributed this lack of awareness to a general distrust in government health 
information due to a history of colonialism and exploitation in Canada, which likely contributed to increased misinformation about COVID-19 risk and spread.

\subsection{Health communication}

The primary modes of communication within Île-à-la-Crosse are radio and social media. These platforms were used throughout the pandemic to communicate health information about COVID-19 case counts and trends. Community members also reported obtaining health information from healthcare practitioners (i.e., for those already visiting a healthcare provider), Elders, and the internet. Key informants indicated an interest in improving digital infrastructure to enable sharing of timely and accurate health information with community members, and minimize misinformation. Key informants also reported room for improvement in the community's digital health infrastructure, particularly in improving timely communication with community members, and to inform decision-making in crisis situations.

\subsection{Digital infrastructure and connectivity}

Île-à-la-Crosse has its own cell tower which offers reliable access to cellular data. The community also has access to internet via the provincial internet provider - Sasktel, as well as a local internet provider - Île-à-la-Crosse Communications Society Inc. Key informants and community members confirmed that most individuals above 13 years of age have access to smartphones, and that these mobile devices are the primary mode of internet access. However, it was unclear whether everyone who owns smartphones also has consistent data plans or home internet connections. Key informants described the great potential of digital devices like smartphones to increase the speed and accuracy of information sharing. Discussions with both key informants and community members suggested the need for a community-specific app or platform which could provide timely health information that was tailored to the community's needs.

Community members noted that expanding digital infrastructure had to be paired with efforts to improve digital literacy - particularly as it relates to data security, privacy, and online misinformation. A separate initiative was discussed which could work to improve digital literacy among youth and Elders, as this would improve both the uptake of digital health platforms, as well as their usefulness and application. Key informants discussed the importance of building digital infrastructure that would enable data sovereignty, self-governance, and determination. The key informants, who are also primary decision-makers in the community, described opportunities for ethical development of digital tools that would ensure that data is owned by the community.

\section{Discussion}

\subsection{Community-based needs assessments in the 21st century}

Rural, and remote communities commonly experience challenges with access to resources and services, including food and other essential supplies, healthcare, and internet connectivity (Oosterveer and Young 2015; Skinner et al. 2016; Goodridge and Marciniuk 2016; Forbes and Edge 2009; McNally et al. 2018; Haight, Quan-Haase, and Corbett 2014). Key informants and community members from our partner community (Île-à-la-Crosse) in a sub-arctic region in Canada corroborated these access issues, particularly in relation to public health. More importantly, digital technology became an important discussion point for offering potential solutions to minimize health inequities. Digital devices, such as smartphones, have become ubiquitous, with currently more than 6 billion smartphone subscription plans globally (O'Dea 2021), and 32 million smartphone users in Canada ( $\mathrm{O}^{\prime}$ Dea 2020). Our engagement with our partner community revealed that smartphone ownership is near universal in their jurisdiction, with $100 \%$ of community members we engaged with across all age and socioeconomic 
cohorts owning smartphones. Digital devices such as smartphones provide access to digital tools and platforms, which range from apps to electronic platforms that provide services and support, to communication in real-time.

In many rural and remote communities, smartphone ownership is not the limiting factor - it is internet inequity, which is defined as differential internet access based on wealth, location (urban, rural, or remote), gender, age, or ethnicity (Katapally 2019). The United Nations has declared internet access a human right (Rights 2011), which makes it imperative to develop digital infrastructure such as internet connectivity to improve digital accessibility. Île-à-la-Crosse has its own cell tower which offers reliable access to cellular data. The community of Île-à-la-Crosse also has access to consistent and dedicated internet service through a provincial internet provider and local internet provider. The needs assessment showed that the universality of smartphone ownership combined with good internet connectivity lays the foundation for the development of tailored, culturally-appropriate digital health tools and platforms in communities like Île-à-la-Crosse.

In particular, the needs assessment revealed that smartphone apps, which most citizens are well-versed with, can be used to provide local services and access to resources. For example, a locally developed app can connect the Mayor's office with community members in real-time to provide updates on COVID-19 outbreaks. Apps also have the potential to connect communities to resources within and outside of the community (Katapally 2020b; Goodridge and Marciniuk 2016). For example, advanced artificial intelligence algorithms can be used to anticipate community needs prior to urgent crises like COVID-19, environmental disasters, or food crises (Katapally 2020b; Gray, Joseph, and Olayiwola 2020; Meechang et al. 2020; Castro and New 2016; Zhou et al. 2019). To date, the issue has not been the lack of technology or ability to bridge this gap for rural and remote communities. Instead, larger systemic inequities have limited our ability to co-create local solutions for global problems by decentralizing technology that is widely available (Katapally 2020b; Katapally 2020c), which highlights upstream inequities in developing digital tools and platforms.

Digital tools and platforms can provide rich data to predict future community crises, however, it is critical to engage with communities ethically to ensure co-creation of digital tools and platforms (Katapally 2020b; 2019; Smith 2021; Datta 2018). In partnership with the Citizen Scientist Advisory Council, this needs assessment is the first step in co-creating such platforms. Digital tool development can also benefit from a Two-Eyed Seeing approach (Martin 2012), where the strengths of Western technology can be combined with Traditional Indigenous Knowledges to capture the rich diversity of community-based knowledge to co-create digital solutions (Bartlett, Marshall, and Marshall 2012). Moreover, the co-created digital tools can be used to share knowledge in real-time with community members and other stakeholders to enable remote engagement, which is especially important during crisis situations such as a pandemic. As we implement creative digital tools in varied programs or research projects, we must also integrate this digital perspective into the evaluation process. Research and evaluation literature has well established approaches to needs assessment evaluations (Saunders, Evans, and Joshi 2005; Watkins, Meiers, and Visser 2012; Stufflebeam and Shinkfield 2007); however, in the 21st century, we need to account for the use and application of digital platforms in community-focused initiatives.

\subsection{Recommendations for inclusive digital needs assessments}

Digital platforms have great potential to collect data, document community knowledge, enable real-time information sharing, and potentially implement programs or services that can be administered remotely. In order to identify how and where digital platforms can play a role in addressing community priorities, we propose several recommendations for inclusive community-based needs assessments. 
First, at the crux of all community-based needs assessments is relationships. A relationship built on respect, reciprocity, mutual understanding, and prioritizing the needs and vision of communities is essential for sustainable impact. The First Nations OCAP® principles (The First Nations Information Governance Centre 2021) informed conversations between the research team and community about data ownership and control. These principles include ownership of knowledge and data, control over all aspects of research, access to information about one's own community, and possession or control of data (The First Nations Information Governance Centre 2021). The OCAP® principles ensure First Nations and other Indigenous Peoples the right to their own information, and also reflect commitments to use and share information in a way that maximizes the benefit to a community, while minimizing harm. Some communities may choose to lead a project, or work closely in collaboration with experts for specific projects. Irrespective of the project dynamics, needs assessments rely on detailed information and context about a community for a project to succeed.

Second, it is important for researchers and evaluators to gain an understanding of the current digital infrastructure and connectivity in the community. The needs assessment framework (Figure 1) includes relevant questions for identifying data and WiFi access in a community, penetration of digital devices, and existing digital infrastructure. Even for community-based initiatives not focused on a digital platform, digital tools will inevitably be a part of the solution, a barrier, or both. Hence the digital landscape has become part of the context that we must capture and understand in a needs assessment to better design and develop programming, policies, and other initiatives.

Third, it is important to ask the question of where and how a digital tool or platform could help. Are there gaps that digital tools can help address or fill? In rural and remote communities, in particular, digital tools can provide access to real-time information and services not otherwise available. For example, TeleHealth (Northern health 2021; Sevean et al. 2009) in the Canadian north offers citizens access to essential healthcare services, including video appointments with medical specialists. Prior to TeleHealth, many residents would need to fly into bigger cities in the nearest province to access health care (Oosterveer and Young 2015).

Lastly, an understanding of the broader context which affects a community's ability to adopt digital tools is critical to the success of digital initiatives. This includes, but is not limited to, capturing data on socioeconomic status and the accessibility of internetconnected digital devices. Digital tools should help to bridge the divide in resource, service and information access - not widen the gap. For some communities, this may require working on building digital infrastructure and obtaining dedicated funds to expand access prior to implementing digital initiatives. In addition, digital literacy cannot be taken for granted. Digital literacy refers to individuals' ability to not only use digital devices, but according to Eshet-Alkalai (Eshet-Alkalai 2004), "includes a large variety of complex cognitive, motor, sociological, and emotional skills, which users need in order to function effectively in digital environments." In its simplest form, digital literacy may include the ability to navigate digital platforms, download apps, and communicate electronically. Other more specific skills include ability to read and understand instructions, terms and services, as well as data privacy and security statements (Tomczyk 2020; Oh et al. 2021; Nouri et al. 2019). As part of a needs assessment, identifying digital literacy within a community is an important step to safe, ethical, and relevant digital tool development.

\subsection{Recognizing the importance of data sovereignty and Indigenous self governance}

Data sovereignty and social justice are important aspects of community-based work, particularly for communities that have experienced discrimination or systemic inequities (Kukutai and Taylor 2016; Smith 2021). Data sovereignty refers to meaningful control and ownership of one's data (Hummel et al. 2021). For Indigenous communities in Canada, self-determination and self-governance are of paramount importance given 
the colonial history of oppression, trauma, and disenfranchisement (Ibarra 2014; Allan and Smylie 2015), and data sovereignty and ownership of digital tools and platforms can promote that independence. In conducting digital community-based needs assessments, the application of a Two-Eyed Seeing lens enables us to leverage strengths of both Indigenous and Western Ways of Knowing to help focus on key priorities and develop solutions.

In the needs assessment with Île-à-la-Crosse, Two-Eyed Seeing involved incorporation of Métis Knowledge during team engagements, which ensured that any digital tools and or platforms developed would incorporate Traditional Knowledge to promote data sovereignty. Based on guidance from community leaders, Elders were approached with respect and ceremony. The Citizen Scientist Advisory Council identified specific digital technology and features that could be of use to the community, and emphasized the need for tailored tools which would contribute to data sovereignty. Discussions with key informants and community members in Île-à-la-Crosse about digital tools that would promote community health centered around citizen ownership of data, community access, and ensuring data privacy and security. The ultimate goal of this approach to data sovereignty is to facilitate decreased dependence on external systems, and use digital solutions for Indigenous self-determination and self-governance.

\subsection{Development of CO-Away}

Conversations with Île-à-la-Crosse about community health and their key priorities led to the development of "CO-Away," a culturally-responsive digital epidemiological platform to monitor, mitigate, and manage COVID-19 outbreaks (Mitacs 2020). The needs assessment concluded that digital tools and platforms can be used for emerging or other existing population health crises within Île-à-la-Crosse and potentially other Indigenous communities. Moreover, to co-create digital platforms, Île-à-la-Crosse Citizen Scientist Advisory Council identified key features to embed in CO-Away, including free virtual care for citizens via a smartphone app at the frontend, and access to anonymized community data on the backend for decision-makers.

The app will provide three key precision medicine services that are specific to each citizen: 1) continuous risk assessment of COVID-19 infection; 2) evidence-based public health communication; and 3) citizen reporting of food availability, access to public services, and COVID-19 symptoms and test results. These culturally-responsive features have been co-created with Métis decision-makers in Île-à-la-Crosse based on imminent community needs and preferences. CO-Away will enable real-time data collection through continuous citizen engagement to inform municipal jurisdictional policies.

There are three guiding principles for developing CO-Away: I) Citizen empowerment and data ownership: Active engagement is enabled through app features such as visualizing community risk. More importantly, the community owns the data to ensure data sovereignty; II) Privacy: Utilizing a cutting-edge methodology called federated machine learning, we will develop artificial intelligence algorithms that stores sensitive data such as participant location on mobile devices itself, i.e., sensitive data is not stored in external servers; III) Security and scalability: The backend server will be located in Cloud in Canada, which allows for horizontal and vertical scalability, i.e., the potential for developing multiple frontend apps and decision-making dashboards.

\section{Conclusions}

Needs assessments can facilitate important conversations in community-based research and evaluation to learn about key priority areas, challenges, and opportunities for growth. Digital tools and tailored platforms can help bridge existing gaps in resource, program, and service access in rural, remote, and northern Canadian communities. In Île-à-la-Crosse, the needs assessment framework has propelled the launch of timely, community-engaged initiatives to address key priority areas for starting with COVID19. 


\section{Patents}

Not applicable.

Supplementary Materials: Not applicable.

Author Contributions: All authors (JB, MCB, KS, DF, TRK) contributed to the manuscript conceptualization. JB, DF, and TRK led community engagement and data collection. JB and TRK conducted analyses. JB and MCB wrote the first draft with contributions from KS, DF and TRK. TRK obtained funding for this project. All authors reviewed and commented on subsequent drafts and provided final approval of the manuscript.

Funding: This study is funded by the Saskatchewan Health Research Foundation Establishment grant \#3779 (TRK).

Data Availability Statement: Not applicable.

Acknowledgments: The authors would like to acknowledge the contributions of community members of Île-à-la-Crosse. The Elders, youth, and key decision-makers who are part of the Île-à-laCrosse Citizen Scientist Advisory Council have been invaluable in providing support, guidance, and cultural training to the research team.

Conflicts of Interest: The authors have no conflicts of interest to declare. 


\section{References}

Allan, Billie, and Janet Smylie. 2015. “First Peoples, Second Class Treatment." First Peoples, Second Class Treatment: The Role of Racism in the Health and Well-Being of Indigenous Peoples in Canada, 1-65. https://www.wellesleyinstitute.com/wpcontent/uploads/2015/02/Summary-First-PeoplesSecond-Class-Treatment-Final.pdf.

Askew, Karyl, Monifa Green Beverly, and Michelle L. Jay. 2012. “Aligning Collaborative and Culturally Responsive Evaluation Approaches." Evaluation and Program Planning 35 (4): 552-57. https://doi.org/10.1016/j.evalprogplan.2011.12.011.

Bartlett, Cheryl, Murdena Marshall, and Albert Marshall. 2012. “Two-Eyed Seeing and Other Lessons Learned within a CoLearning Journey of Bringing Together Indigenous and Mainstream Knowledges and Ways of Knowing." Journal of Environmental Studies and Sciences 2 (4): 331-40. https://doi.org/10.1007/s13412-012-0086-8.

Cairncross, Liz, C Morrell, J Darke, and S Brownhill. 2002. Tenants Managing: An Evaluation of Tenant Management Organizations in England. London: Office of the Deputy Prime Minister.

Cameco Corp. 2020. “Patuanak - English River First Nation - Community Profiles - Community - Cameco Northern Saskatchewan." 2020.

Carr-Hill, Roy, and Andrew D Street. 2008. “Economic Analysis of Cost-Effectiveness of Community Engagement to Improve Health." http://ideas.repec.org/p/chy/respap/33cherp.html.

Castro, Daniel, and Joshua New. 2016. “The Promise of Artificial Intelligence.” Texas Medicine 115 (10): 32-35. https://doi.org/10.7551/mitpress/12385.001.0001.

Central Urban Métis Federation Inc., Kinistin Saulteaux Nation, and Saskatoon Health Region. 2010. "Strengthening the Circle: Partnering for Improved Health for Aboriginal People." Saskatoon, SK.

Chouinard, Jill Anne, and Fiona Cram. 2020. “Culturally Responsive Approaches to Evaluation: Empirical Implications for Theory and Practice." Thousand Oaks, California. https://doi.org/10.4135/9781506368559.

Cyril, Sheila, Ben J. Smith, Alphia Possamai-Inesedy, and Andre M.N. Renzaho. 2015. “Exploring the Role of Community Engagement in Improving the Health of Disadvantaged Populations: A Systematic Review." Global Health Action 8. https://doi.org/10.3402/gha.v8.29842.

Datta, Ranjan. 2018. "Decolonizing Both Researcher and Research and Its Effectiveness in Indigenous Research." Research Ethics 14 (2): 1-24. https://doi.org/10.1177/1747016117733296.

Eshet-Alkalai, Yoram. 2004. “Digital Literacy: A Conceptual Framework for Survival Skills in the Digital Era." Journal of Educational Multimedia and Hypermedia 13: 93-106.

Favel, Mayor Dwayne, and Gerald Roy. 2013. “Northern Village of Ile a La Crosse.”

Fetterman, David M. 1994. “Empowerment Evaluation.” Evaluation Practice 15 (1): 577-83. https://doi.org/10.1016/B978-0-08-0970868.10572-0.

Forbes, Dorothy, and Dana Edge. 2009. “Canadian Home Care Policy and Practice in Rural and Remote Settings: Challenges and Solutions." Journal of Agromedicine 14 (2): 119-24. https://doi.org/10.1080/10599240902724135.

Frohlich, Katherine L., Nancy Ross, and Chantelle Richmond. 2006. “Health Disparities in Canada Today: Some Evidence and a Theoretical Framework." Health Policy 79 (2-3): 132-43. https://doi.org/10.1016/j.healthpol.2005.12.010.

Goodridge, Donna, and Darcy Marciniuk. 2016. “Rural and Remote Care.” Chronic Respiratory Disease 13 (2): $192-203$. https://doi.org/10.1177/1479972316633414.

Gracey, Michael, and Malcolm King. 2009. “Indigenous Health Part 1: Determinants and Disease Patterns." The Lancet 374 (9683): 65-75. https://doi.org/10.1016/S0140-6736(09)60914-4.

Gray, Darrell M., Joshua J. Joseph, and J. Nwando Olayiwola. 2020. “Strategies for Digital Care of Vulnerable Patients in a COVID19 World -Keeping in Touch." JAMA Health Forum 1 (6): e200734. https://doi.org/10.1001/jamahealthforum.2020.0734.

Haight, Michael, Anabel Quan-Haase, and Bradley A. Corbett. 2014. “Revisiting the Digital Divide in Canada: The Impact of 
Demographic Factors on Access to the Internet, Level of Online Activity, and Social Networking Site Usage." Information Communication and Society 17 (4): 503-19. https://doi.org/10.1080/1369118X.2014.891633.

Health Quality Ontario. 2009. “Needs Assessment Resource Guide for Family Health Teams.” Journal of Continuing Education in Nursing 37 (4): 148-49. https://doi.org/10.3928/00220124-20060701-02.

Hummel, Patrik, Matthias Braun, Max Tretter, and Peter Dabrock. 2021. “Data Sovereignty: A Review.” Big Data and Society 8 (1). https://doi.org/10.1177/2053951720982012.

Ibarra, Oscar H. 2014. APDCM Introduction and Committees. Proceedings - IEEE 28th International Parallel and Distributed Processing Symposium Workshops, IPDPSW 2014. https://doi.org/10.1109/IPDPSW.2014.214.

Iwama, Marilyn, Murdena Marshall, Albert Marshall, and Cheryl Bartlett. 2009. “Two-Eyed Seeing and the Language of Healing in Community-Based Research." Canadian Journal of Nature Education 32 (2): 3-23.

Jull, Janet, Audrey Giles, and Ian D. Graham. 2017. “Community-Based Participatory Research and Integrated Knowledge Translation: Advancing the Co-Creation of Knowledge." Implementation Science 12 (1): 1-9. https://doi.org/10.1186/s13012-0170696-3.

Katapally, Tarun, Prasanna Kannan, and Eric Kwabia. 2021. “Citizen Science and COVID : Identifying the Needs of Rural and Remote Education COVID-19 SERIES : FROM CRISIS TO RECOVERY This Issue of JSGS Policy Brief Is Part of a Series Dedicated to Exploring And."

Katapally, Tarun R. 2019. “The SMART Framework: Integration of Citizen Science, Community-Based Participatory Research, and Systems Science for Population Health Science in the Digital Age." JMIR MHealth and UHealth 7 (8): 1-12. https://doi.org/10.2196/14056.

- - - 2020a. “Global Digital Citizen Science Policy for Pandemics.” Journal of Medical Internet Research 22 (April): e19357. https://doi.org/10.2196/preprints.19357.

- - . 2020b. "A Global Digital Citizen Science Policy to Tackle Pandemics like COVID-19." Journal of Medical Internet Research 22 (5): 1-7. https://doi.org/10.2196/19357.

- - . 2020c. "Are Democratic Nations Ready to Democratize Technology?: Tarun Katapally for Inside Policy." https://www.macdonaldlaurier.ca/democratic-nations-democratize-technology/.

King, Malcolm, Alexandra Smith, and Michael Gracey. 2009. “Indigenous Health Part 2: The Underlying Causes of the Health Gap." The Lancet 374 (9683): 76-85. https://doi.org/10.1016/S0140-6736(09)60827-8.

Kukutai, Tahu, and John Taylor. 2016. Indigenous Data Sovereignty. Acton: ANU Press. https://doi.org/10.1109/IPDPSW.2014.214.

Marrone, Sonia. 2007. “Understanding Barriers to Health Care: A Review of Disparities in Health Care Services among Indigenous Populations." International Journal of Circumpolar Health 66 (3): 188-98. https://doi.org/10.3402/ijch.v66i3.18254.

Marsh, Teresa Naseba, Diana Coholic, Sheila Cote-Meek, and Lisa M. Najavits. 2015. Honouring the Truth, Reconciling for the Future Honouring the Truth, Reconciling for the Future Summary of The. Harm Reduction Journal. Vol. 12.

Martin, Debbie H. 2012. “Two-Eyed Seeing: A Framework for Indigenous Approaches to Indigenous Health Research.” Canadian Journal of Nursing Research 44 (2): 20-42.

Mason, Anne R., Roy Carr Hill, Lindsey A. Myers, and Andrew D. Street. 2008. “Establishing the Economics of Engaging Communities in Health Promotion: What Is Desirable, What Is Feasible?" Critical Public Health 18 (3): 285-97. https://doi.org/10.1080/09581590802277366.

McLennan, David. n.d. "Sakitawak Development's Facebook Page."

McNally, Michael B., Dinesh Rathi, Kris Joseph, Jennifer Evaniew, and Amy Adkisson. 2018. “Ongoing Policy, Regulatory, and Competitive Challenges Facing Canada's Small Internet Service Providers." Journal of Information Policy 8: 167-98. https://doi.org/10.5325/jinfopoli.8.2018.0167.

Meechang, Kunruthai, Natt Leelawat, Jing Tang, Akira Kodaka, and Chatpan Chintanapakdee. 2020. “The Acceptance of Using 
Information Technology for Disaster Risk Management: A Systematic Review." Engineering Journal 24 (4): 111-32. https://doi.org/10.4186/ej.2020.24.4.111.

Mitacs. 2020. “CO-Away: A Digital Tool to Help Northern Communities Address COVID-19.” 2020.

https://www.mitacs.ca/en/impact/co-away-digital-tool-help-northern-communities-address-covid-19.

Narayan, Deepa. 2002. Empowerment and Pverty Reduction: A Sourcebook. Washington, D.C.; World Bank.

Northern health. 2021. “Telehealth.” 2021. https://www.northernhealth.ca/services/digital-health/telehealth.

Nouri, Sarah S., Patricia Avila-Garcia, Anupama Gunshekar Cemballi, Urmimala Sarkar, Adrian Aguilera, and Courtney Rees Lyles. 2019. “Assessing Mobile Phone Digital Literacy and Engagement in User-Centered Design in a Diverse, Safety-Net Population: Mixed Methods Study." JMIR MHealth and UHealth 7 (8): 1-11. https://doi.org/10.2196/14250.

O’Dea, S. 2020. “Number of Smartphone Users in Canada from 2018 to 2024 (in Millions)." 2020. https://www.statista.com/statistics/467190/forecast-of-smartphone-users-in-canada/.

- - - 2021. “Number of Smartphone Users from 2016 to 2021.” 2021. https://www.statista.com/statistics/330695/number-ofsmartphone-users-worldwide/.

O’Donnell, Susan, Brian Beaton, Rob McMahon, Heather E Hudson, Denise Williams, and Tim Whiteduck. 2016. “Digital Technology Adoption in Remote and Northern Indigenous Communities in Canada." Canadian Sociological Association 2016 Annual Conference, 1-44.

Oh, Sarah Soyeon, Kyoung A. Kim, Minsu Kim, Jaeuk Oh, Sang Hui Chu, and Ji Yeon Choi. 2021. “Measurement of Digital Literacy among Older Adults: Systematic Review." Journal of Medical Internet Research 23 (2): 1-15. https://doi.org/10.2196/26145.

Oosterveer, Tim Michiel, and T. Kue Young. 2015. “Primary Health Care Accessibility Challenges in Remote Indigenous Communities in Canada's North." International Journal of Circumpolar Health 74: 1-7. https://doi.org/10.3402/ijch.v74.29576.

Pelletier, Chelsea A., Anne Pousette, Kirsten Ward, and Gloria Fox. 2020. “Exploring the Perspectives of Community Members as Research Partners in Rural and Remote Areas." Research Involvement and Engagement 6 (1): 1-10. https://doi.org/10.1186/s40900-020-0179-6.

Popay, J., P. Attree, D. Hornby, B. Milton, M. Whitehead, B. French, U Kowarzik, and N. Simpson. 2007. “Community Engagement to Address the Wider Social Determinants of Health: A Review of Evidence on Impact, Experience \& Process," no. February 2014. http://www.nice.org.uk/guidance/index.jsp?action=folder\&o=34709.

Pratchett, Lawrence, Vivien Lowndes, Graham Smith, Gerry Stoker, Corinne Wales, and Catherine Durose. 2009. Empowering Communities to Influence Local Decision Making. Governance An International Journal Of Policy And Administration.

Public Health Agency of Canada. 2018. "Key Health Inequalities in Canada: A National Portrait.” https://www.canada.ca/content/dam/phac-aspc/documents/services/publications/science-research/key-health-inequalitiescanada-national-portrait-executive-summary/hir-full-report-eng.pdf.

Rights, Office of the United Nations High Commissioner for Human. 2011. "Report of the Special Rapporteur on the Promotion and Protection of the Right to Freedom of Opinion and Expression, Frank La Rue." Creating Citizenship in the NineteenthCentury South. Southampton: NIHR Journals Library. https://doi.org/10.1093/jahist/jau290.

Saunders, Ruth P., Martin H. Evans, and Praphul Joshi. 2005. “Developing a Process-Evaluation Plan for Assessing Health Promotion Program Implementation: A How-To Guide." Health Promotion Practice 6 (2): 134-47. https://doi.org/10.1177/1524839904273387.

Sevean, Pat, Sally Dampier, Michelle Spadoni, Shane Strickland, and Susan Pilatzke. 2009. “Patients and Families Experiences with Video Telehealth in Rural/Remote Communities in Northern Canada." Journal of Clinical Nursing 18 (18): $2573-79$. https://doi.org/10.1111/j.1365-2702.2008.02427.x.

Skinner K, Burnett K, Pratley E, Parker B, Dovick B. (2021). Chapter 13. Case Study 2: Engaging Youth in a Needs Assessment for Programming and Evaluation. In A. Sixsmith, J. Sixsmith, A. Mihailidis, and M. Fang (Eds.), Knowledge, Innovation and 
Impact: A Guidebook for the Engaged Health Researcher (pp. 97-100). New York, NY: Springer.

Skinner, Kelly, Kristin Burnett, Patricia Williams, Debbie Martin, Christopher Stothart, Joseph LeBlanc, Gigi Veeraraghavan, and Amanda Sheedy. 2016. "Challenges in Assessing Food Environments in Northern and Remote Communities in Canada." Canadian Journal of Public Health 107 (June): eS60-63. https://doi.org/10.17269/CJPH.107.5324.

Smith, Linda Tuhiwai. 2021. Decolonizing Methodologies: Research and Indigenous Peoples. Networks of Music and Culture in the Late Sixteenth and Early Seventeenth Centuries: A Collection of Essays in Celebration of Peter Philips's 450th Anniversary. London; New York; Dunedin: Zed Books Ltd; University of Otago Press; Distributed in the USA exclusively by St Martin's Press. https://doi.org/10.4324/9781315597843-10.

Statistics Canada. 2017. "Île-à-La-Crosse, NV [Census Subdivision], Saskatchewan and Saskatchewan [Province] (Table).” Ottawa. https://doi.org/Statistics Canada Catalogue no. 98-316-X2016001.

Stufflebeam, Daniel L., and Anthony J. Shinkfield. 2007. Evaluation Theory, Models, and Applications. 1st ed. San Francisco, CA: Jossey-Bass.

Sylvestre, Paul, Heather Castleden, Debbie Martin, and Mary McNally. 2018. “'Thank You Very Much... You Can Leave Our Community Now.': Geographies of Responsibility, Relational Ethics, Acts of Refusal, and the Conflicting Requirements of Academic Localities in Indigenous Research." Acme 17 (3): 750-79.

“The Encyclopedia of Saskatchewan: Île-à-La-Crosse." n.d.

The First Nations Information Governance Centre. 2021. “The First Nations Principles of OCAPтM Training Course.” 2021. https://fnigc.ca/ocap-training.

Tomczyk, Łukasz. 2020. “Skills in the Area of Digital Safety as a Key Component of Digital Literacy among Teachers." Education and Information Technologies 25 (1): 471-86. https://doi.org/10.1007/s10639-019-09980-6.

Voegeli, Christopher. 2021. “Evaluation Advisory Groups: Considerations for Design and Management." Canadian Journal of Program Evaluation. https://doi.org/10.3138/cjpe.69949.

Waldram, James Burgess, Ann Herring, and T. Kue Young. n.d. Aboriginal Health in Canada: Historical, Cultural, and Epidemiological Perspectives. 2nd editio. Toronto: University of Toronto Press.

Wallerstein, Nina, Bonnie Duran, John G. Oetzel, and Meredith Minkler. 2017. Community-Based Participatory Research for Health: Advancing Social and Health Equity.

Watkins, Ryan, Maurya West Meiers, and Yusra Laila Visser. 2012. Section 1 - Needs Assessment:Frequently Asked Questions. A Guide to Assessing Needs. https://doi.org/10.1596/9780821388686_ch02.

Wehipeihana, Nan, E Jane Davidson, and Kate Mckegg. 2010. “What Does It Take to Do Evaluation in Communities and Cultural Contexts Other Than Our Own?" Journal of MultiDisciplinary Evaluation 6 (13): 182-92.

Whitelaw, Sera, Mamas A. Mamas, Eric Topol, and Harriette G.C. Van Spall. 2020. “Applications of Digital Technology in COVID19 Pandemic Planning and Response." The Lancet Digital Health 2 (8): e435-40. https://doi.org/10.1016/S2589-7500(20)30142-4.

Zhou, Lei, Chu Zhang, Fei Liu, Zhengjun Qiu, and Yong He. 2019. “Application of Deep Learning in Food: A Review.” Comprehensive Reviews in Food Science and Food Safety 18 (6): 1793-1811. https://doi.org/10.1111/1541-4337.12492. 